\title{
ATUALIZAÇÃO ELETRÔNICA DO LAMINADOR DE BARRAS E FIO MÁQUINA DA VETORIAL PARAGUAY*
}

Alexandre Rizek Schultz

\section{Resumo}

Esse projeto visou à substituição do sistema de controle instalado no laminador de barras e fio-máquina, por um novo e moderno sistema de controle. Este novo sistema irá controlar o laminador de barras e de rolos instalado na Usina da Vetorial, no Paraguay. Juntamente com a atualização do sistema de controle, a RUSSULA irá substituir os antigos e descontinuados conversores de corrente contínua VERITRON, fornecendo kit's de digitalização e aproveitando os tiristores antigos, porem confiáveis. Na cabine central serão instaladas ferramentas para facilitar a operação do laminador e equipamentos, com novas telas de operação, sistema de aquisição de dados de alta velocidade, sistema de gerenciamento de intertravamentos, dentre outros. O PLC existente, um BBC Procontic, será inteiramente substituído por novos S7-1500, nova linha de PLC's Siemens. O novo sistema irá possibilitar aumento de produtividade, diminuição de paradas, diminuição de perdas metálicas e maior confiabilidade no controle.

Palavras-chave: RUSSULA; VERITRON; Laminador, PLC; S7-1500.

\section{BAR AND WIRE ROD ROLLING MILL CONTROL SYSTEM UPDATE AT VETORIAL PARAGUAY}

\section{Abstract}

This project aimed at replacing the control system installed on the Bar and Wire\&Rod Mill, by a new and modern control system. The new system will control the bar and wire\&rod mill installed at the VETORIAL PARAGUAY in Paraguay. With the update of the control system, the old and discontinued VERITRON direct current converters, will be replaced. Russula will providing digitalization kit's using the old but reliable thyristor. In the main pulpit will be installed tools to facilitate the operation of the mill, like new screens, data acquisition system of high speed, management system of interlocks, among others. The existing PLC, a BBC Procontic, will be entirely replaced by new S7-1500, new line of PLC's Siemens. The new system will enable increased productivity, decreased metal loss and greater reliability.

Keywords: RUSSULA; VERITRON; Rolling Mill; PLC; S7-1500.

1 Engenheiro Elétrico, formado pela Faculdade Mauá de Tecnologia, Diretor da Russula South América com escritório em São Paulo, Brasil. 


\section{INTRODUÇÃO}

Os principais produtos produzidos neste laminador são barras redondas para construção civil que variam de $6,3 \mathrm{~mm}^{2}$ até $32 \mathrm{~mm}^{2}$, sendo $6,3 \mathrm{~mm}^{2}$ em rolos e de $8 \mathrm{~mm}^{2}$ a $32 \mathrm{~mm}^{2}$ no leito de resfriamento. Além de barras redondas para construção civil, o laminador também produz redondos lisos na linha de fio-maquina, sendo entre $5,5 \mathrm{~mm}^{2}$ e $16 \mathrm{~mm}^{2}$.

O Laminador tem uma configuração já ultrapassada, mas muito vista em laminadores na época. Após o reaquecimento do tarugo em um forno de reaquecimento tipo walking Heart de 30 ton $/ \mathrm{h}$, aquecido com gás de Alto Forno, 0 tarugo segue para uma sequencia de passes de laminação em um TRIO desbastador aberto, seguindo então para outro passe em um DUO, finalizando os passes na região que chamamos de DESBASTE.

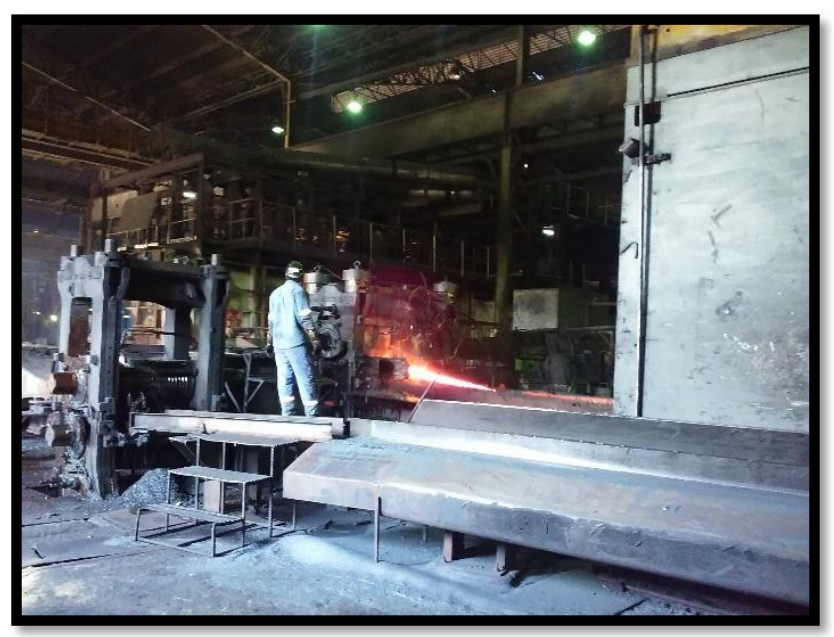

Após sair do desbaste, a barra segue para o TREM DE LAMINAÇAO INTERMEDIÁRIO (LAM IM), que é onde se inicia o escopo de fornecimento do projeto em questão. O laminador intermediário é formado por uma tesoura para despontar de cabeça e cauda da barra, seis gaiolas horizontais e outra tesoura starstop de corte a medida, com função também de despontar cabeça e cauda, quando laminando por rolos.

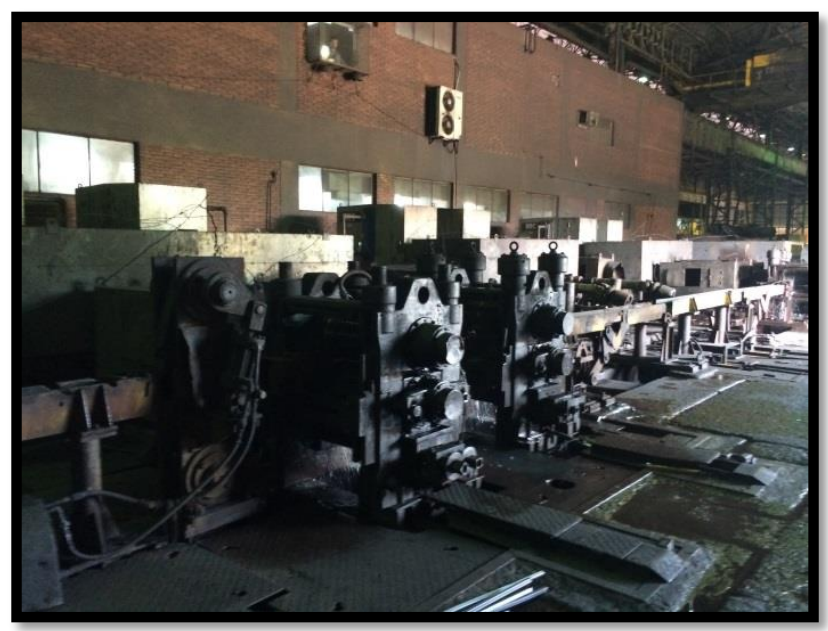


Após o intermediário, a barra pode seguir para o leito de resfriamento. Neste caso a barra será cortada na tesoura de corte a medida, em múltiplos de no comprimento comercial e seguirá para a calha de frenagem (hidráulica) e será posicionada no leito de resfriamento. Uma vez resfriada, seguirá para os caminhos de rolos, tesoura dde corte a frio (batente fixo), e amarração.

A outra opção é a barra seguir para linha de fio-maquina, linha de rolos. Neste caso após o desponte de cabeça na tesoura start-stop, a barra seguirá para o laminador acabador, um bloco MORGAN de 6 passes, caixas d'agua para resfriamento do material, pinch-roll e formador de espiras. Uma vez que as espiras são formadas, estas são depositadas no Stelmor e ao final do Stelmor, a bobina é formada no formador de espiras.
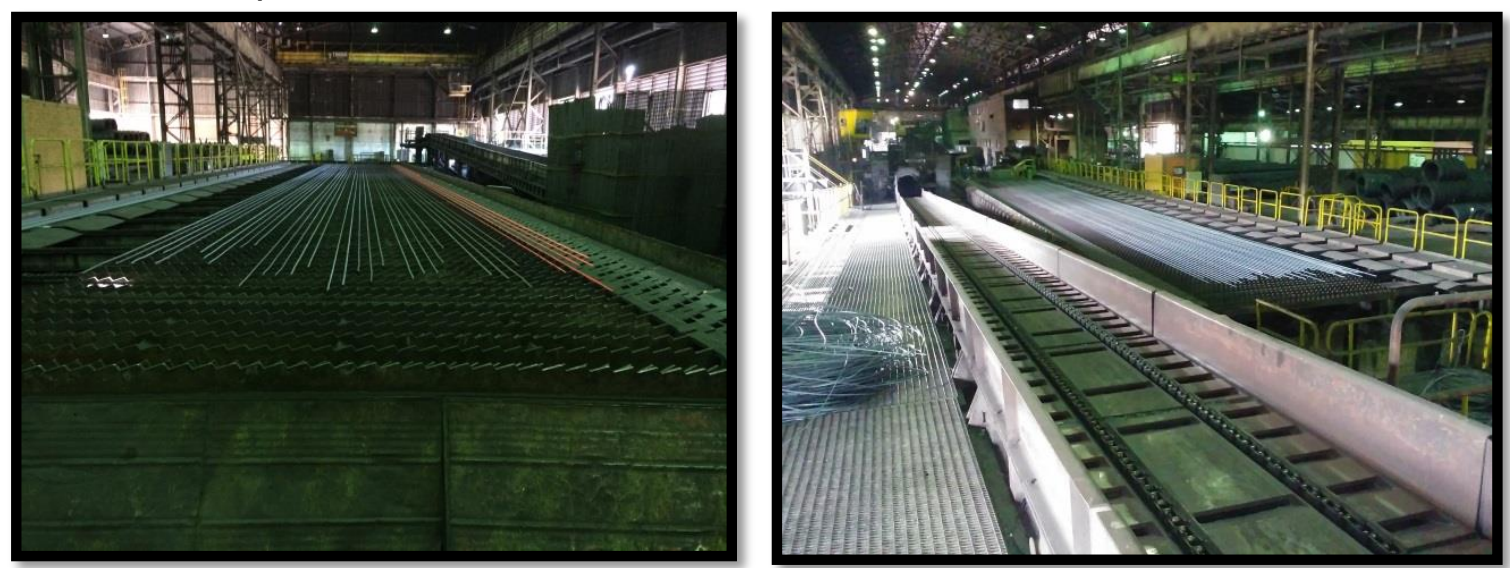

escopo do projeto foi de atualizar eletro e eletronicamente os equipamentos de controle do laminador, como acionamentos, PLC's, HMI dentre outros, com objetivo de tornar a operação do laminador mais confiável, mais produtiva e melhorar alguns KPI's como rendimento metálico, disponibilidade do laminador, índices de paradas operacionais e elétricas.

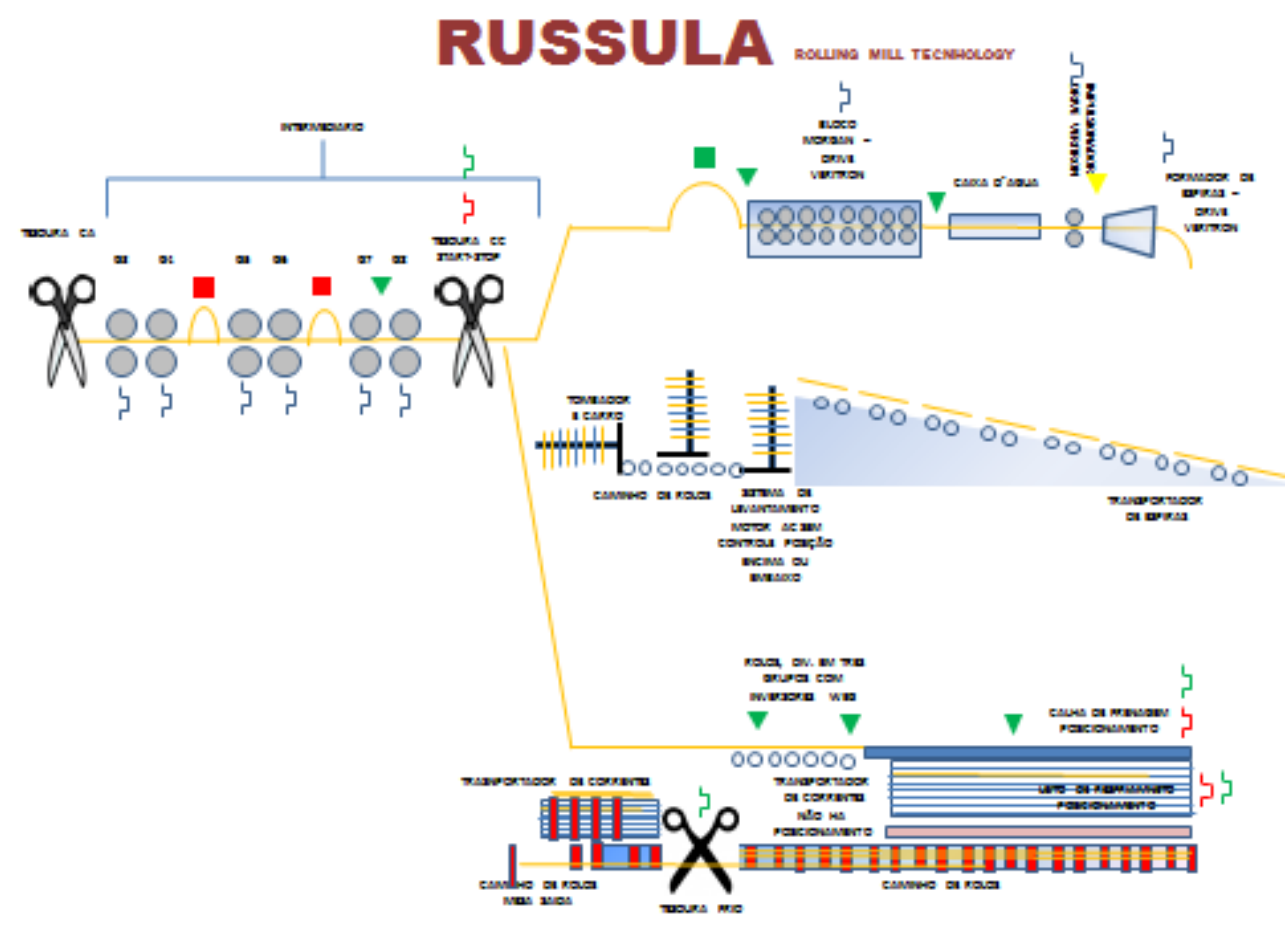




\section{MATERIAIS E MÉTODOS}

Mesmo antes da assinatura do contrato, ainda em fase de definição do projeto, foram feitas pela RUSSULA diversas visitas e estudos no laminador, com objetivo de fazer feito um levantamento detalhado de todos os equipamentos elétricos e eletrônicos instalados no laminador, assim como todos os sistemas e controles existentes. Como resultado se apresentou à Vetorial um relatório em forma de proposta técnica de possíveis melhorias, equipamentos obsoletos que deveriam ser substituídos apresentando o risco em não faze-lo, os equipamentos obsoletos que poderiam ser mantidos e os prováveis ganhos com as melhorias propostas. Este trabalho foi fundamental para a correta tomada de decisão em ir adiante com 0 projeto.

Tendo esses itens em vista foram encontrados pontos de melhoria, como:

$\checkmark$ Reestabelecer o funcionamentos dos laços horizontais do Laminador Intermediário e do laço antes do bloco MORGAN

$\checkmark$ Substituir os Acionamentos antigos VERITRON;

$\checkmark$ Substituir os PLC's existentes BBC Procontic;

$\checkmark$ Instalar sensores de campo onde necessário como: Loop Scanner, Geradores de Pulso, HMD's;

$\checkmark$ Instalação de SIMOTION para posicionamento das tesouras;

$\checkmark$ Integração do sistema lba;

$\checkmark$ Controles de partida e parada de drives;

$\checkmark$ Cascata de velocidades (Distribuição de Referência);

$\checkmark$ Controle de Mínima tensão;

$\checkmark$ Controle de Laço;

$\checkmark$ Detecção automática de sucata;

$\checkmark$ Posicionamento das tesouras de corte.

\subsection{Arquitetura de Controle}

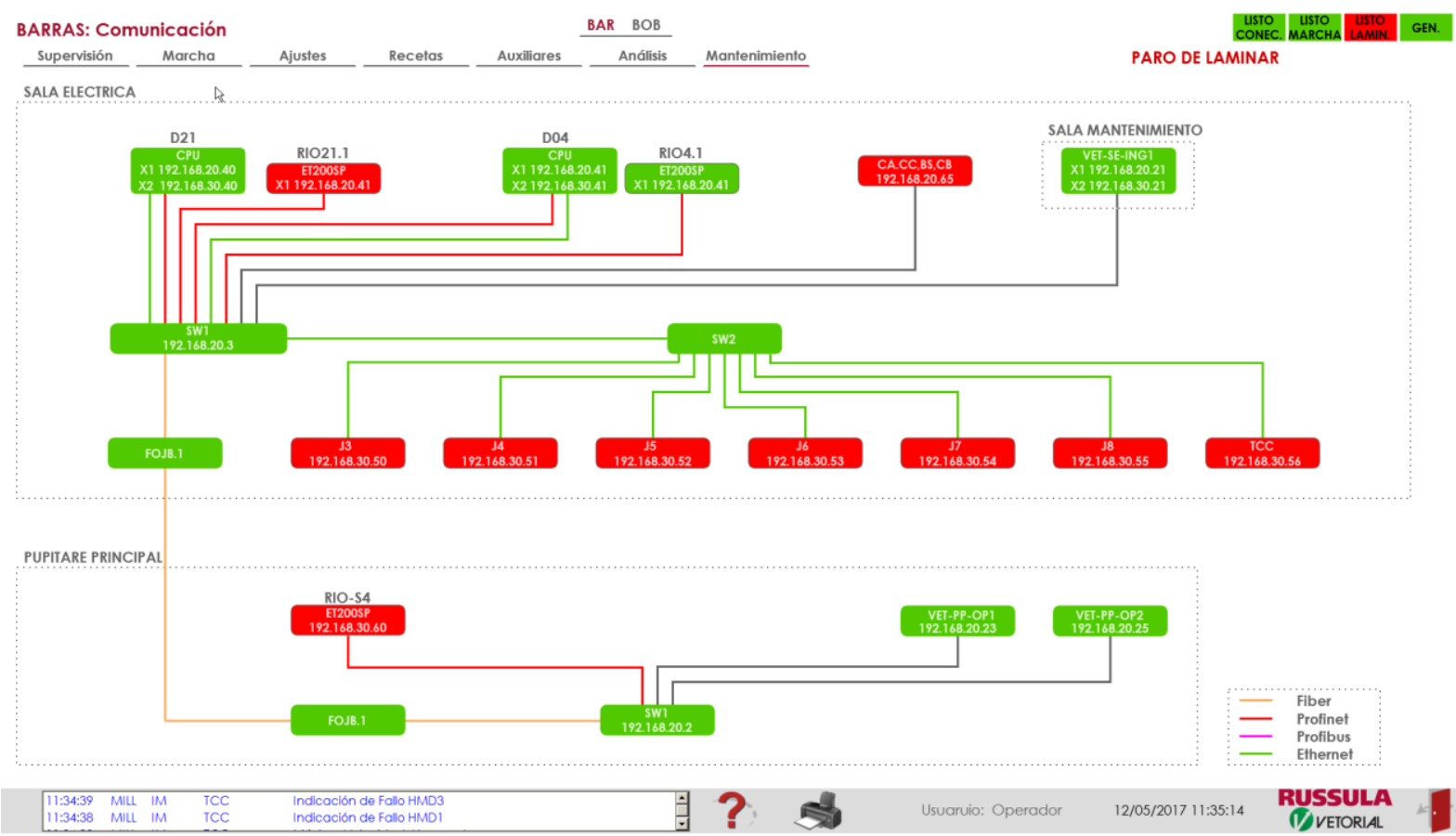


Figura 1. Tela de Supervisão da Infraestrutura de Comunicação.

De todos os itens, uma dos mais importantes foi implementar um sistema de controle confiável e independente de operação. Para isso foram previstos PLC's Siemens S71500, novo substituto do S7-400, já em processo de descontinuação, sistemas de aquisição de dados lba, acionamentos KIT RETROFIT ABB DCR DCS800. Para a cabine operação foi desenvolvida um sistema HMI que possibilita ao operador ter em tempo real todas as informações para correta tomada de decisão, além de importantes ferramentas de manutenção. Em particular, estes sistemas para manutenção e gerenciamento de Intertravamentos, são fundamentais para aumento do índice de disponibilidade do laminador.

Para rede de controle entre PLC's e Remotas será PROFINET.

Para posicionamento da tesoura star-stop, foi definido a solução com utilização do HW Siemens para posicionamento de eixos, em que temos ótima precisão de cortes.

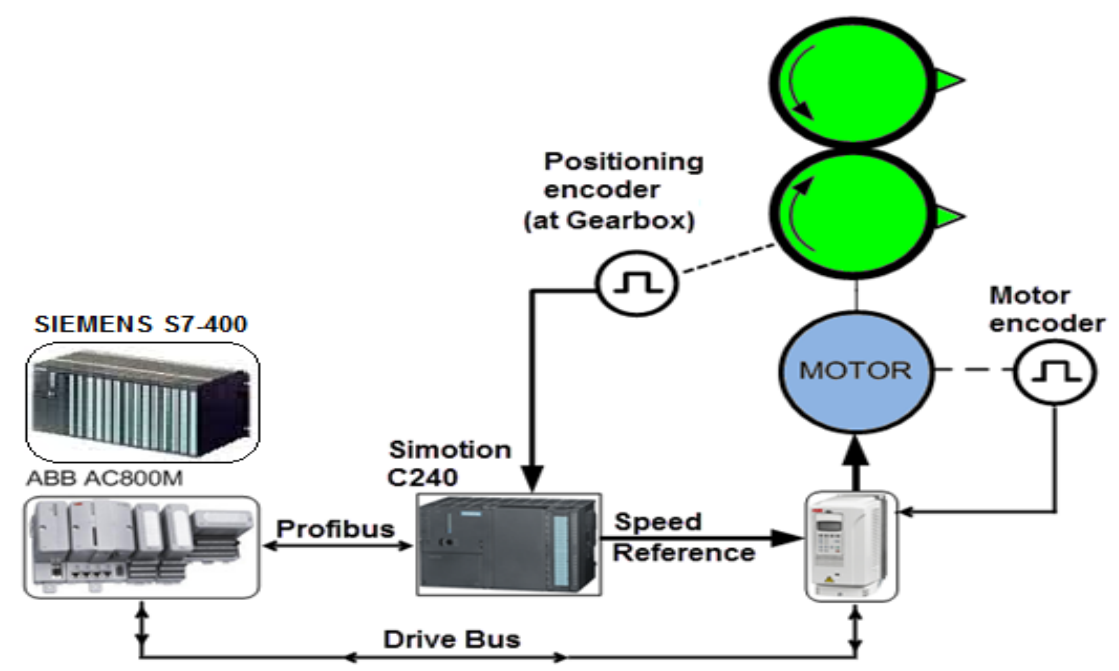

Figura 2. Controle de Posicionamento com SIMOTION.

\subsection{Principais Funções de Controle Implementadas}

\section{$\checkmark$ Receitas de Laminação}

O sistema de receitas de laminação foi projetado para permitir ao operador elaborar uma biblioteca contendo as configurações dos acionamentos de um laminador para cada uma das dimensões mais frequentes de material laminado. As receitas são identificadas e relacionadas em função da bitola do material.

O operador pode fácil e rapidamente modificar e regravar os programas de laminação para reutilização e, desta forma, aperfeiçoar gradativamente o processo de laminação. Os programas podem ser armazenados a partir de valores reais ajustados durante a laminação, ou diretamente pelo operador por meio do teclado.

Cada programa de laminação contém basicamente a configuração do laminador, "Fatores R", fatores de canal ("Groove") de cada acionamento, velocidade de produção (velocidade periférica da última cadeira de laminação), bem como 
sobrevelocidade e dados específicos de equipamentos auxiliares (tesouras, impulsionadores, etc).

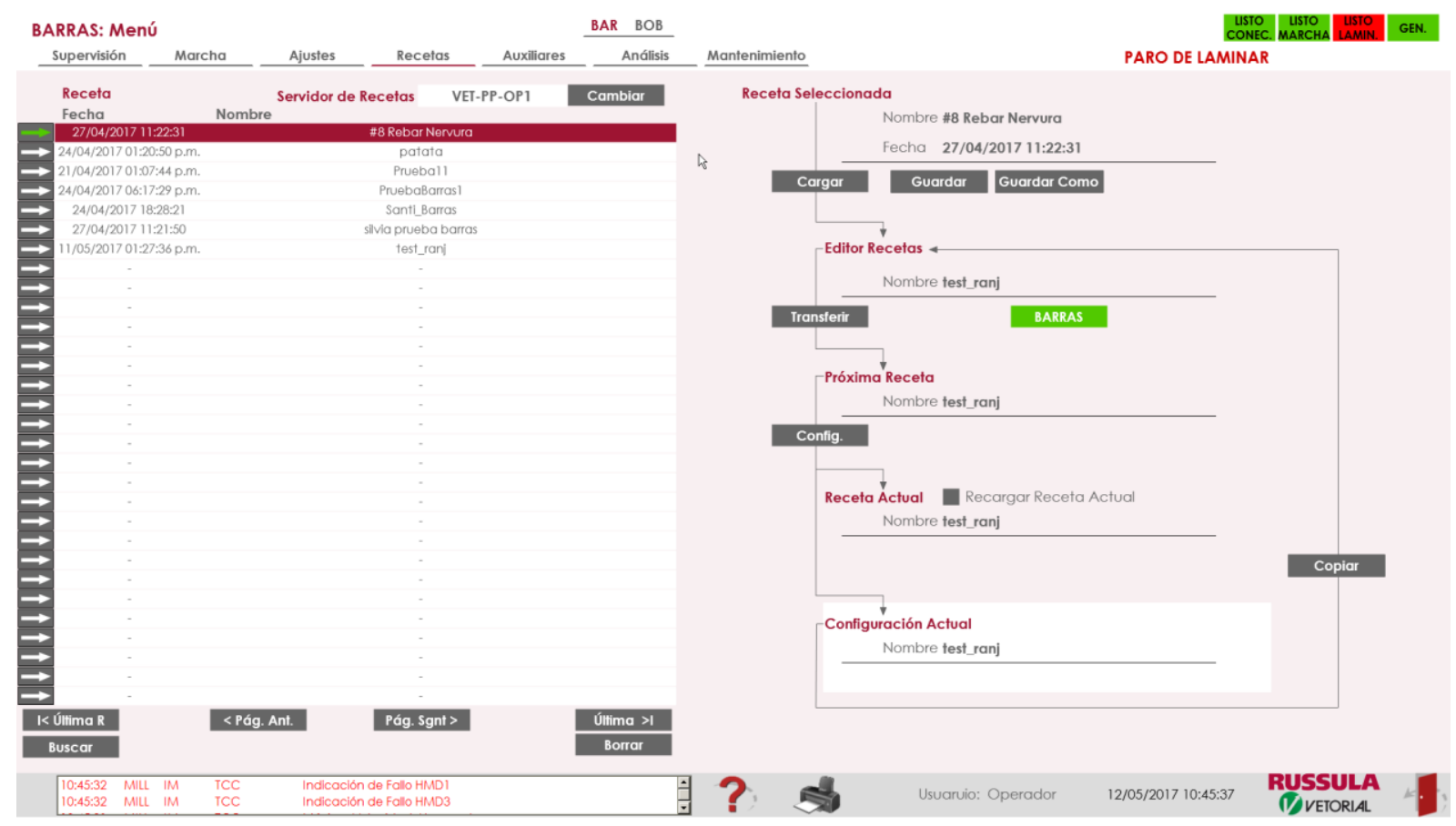

Figura 3. Estrutura de Receitas.

\section{$\checkmark$ Distribuição de Referencia}

A distribuição de referências consiste em um sistema de cascata que gera as referências de velocidade dos motores principais em todo laminador. Essa cascata age normalmente na direção da última para a primeira gaiola de laminação com o propósito de manter constante a velocidade do material nessa última gaiola.

O sistema de controle utiliza a velocidade de produção inserida pelo operador para o cálculo da rotação a ser aplicada no motor de modo a obtermos a velocidade periférica desejada na última gaiola do laminador.

Para esse cálculo necessitamos das seguintes variáveis:

- Fator de "Groove" e diâmetro do rolo, inseridos pelo operador;

- Redução do motor e valor máximo de rpm, parâmetros fixos do laminador.

A velocidade periférica de saída de uma gaiola de laminação pode ser calculada usando a seguinte fórmula:

$$
\text { VelocidadeLinear }_{[m / s]}=\frac{(\text { Dia }- \text { Groove }) * \pi * r p m}{60.000 * i}
$$

onde:

Figura 6. Cálculo Velocidade Linear.

$$
\begin{aligned}
& \text { Dia }=\text { Diâmetro do cilindro }[\mathrm{mm}] \\
& \text { Groove = Fator "Groove" [mm] } \\
& \pi=3,141592 \\
& \text { rpm = velocidade do motor [rotações } / \mathrm{min}] \\
& \mathrm{i}=\text { redução caixa de engrenagem }
\end{aligned}
$$


Para a gaiola anterior dividimos a velocidade de produção pelo Fator "R" da última gaiola, obtendo assim a velocidade de saída da gaiola anterior. De posse de valor aplicamos o mesmo cálculo e variáveis acima para encontrarmos a rotação correta da penúltima gaiola. Esse procedimento é repetido até a primeira gaiola de laminação. Essa cadeia de cálculo é denominada cascata principal "upstream".

O sistema de controle utiliza internamente a unidade métrica para os cálculos, já os valores apresentados nas telas da IHM podem ser em outro sistema (por exemplo, o sistema "imperial").

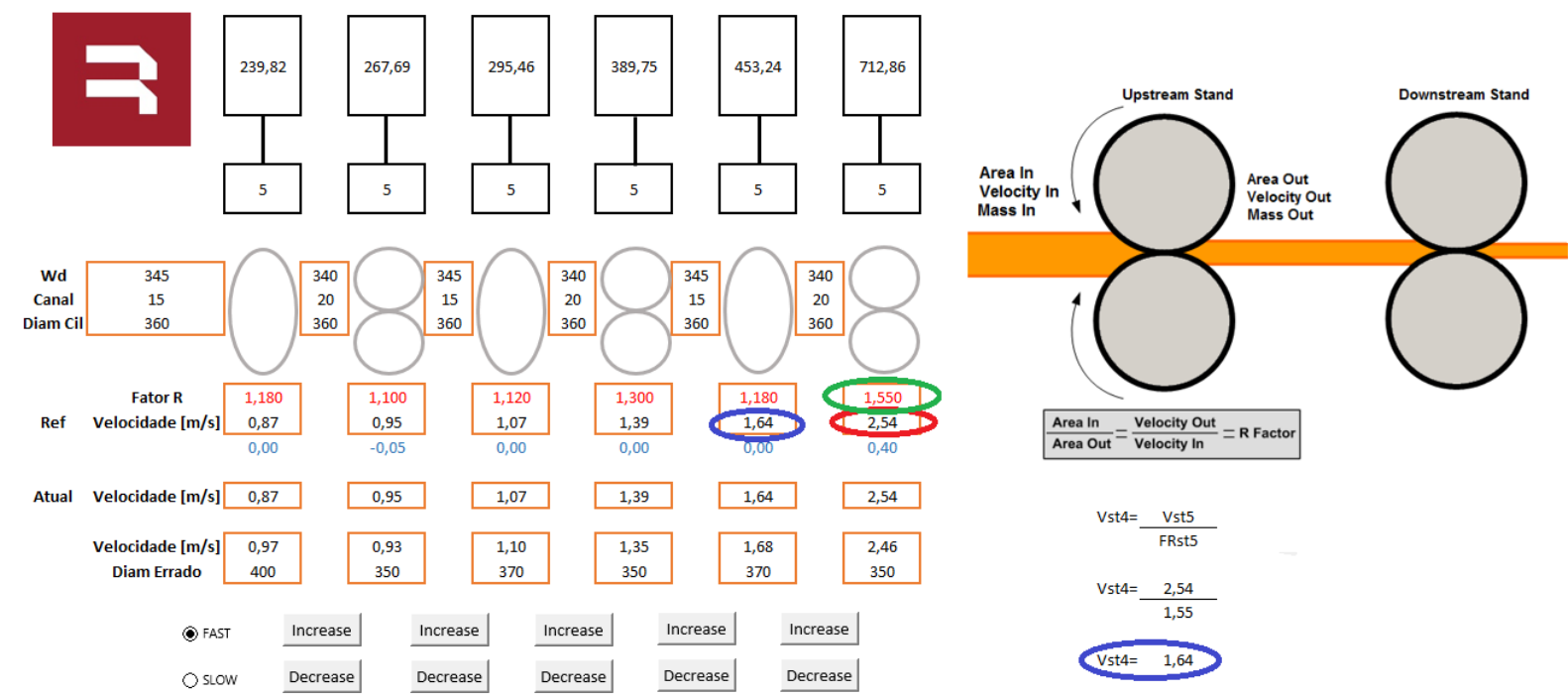

Figura 4. Fator R.

\section{$\checkmark$ Controle de Tração}

O sistema de controle de tração garante que a barra seja laminada com uma tração mínima. O operador ajusta a tração (força/área) necessária que é transformada em torque de laminação. O torque do motor da gaiola "upstream" é medido e a velocidade é ajustada de modo a manter um nível desejado do torque na gaiola.

As tomadas instantâneas do torque da gaiola "upstream" são obtidas quando a cabeça da barra está próxima à gaiola "downstream". Esse torque deve ser memorizado antes de atingir a gaiola "downstream", evitando inclusive a guia de entrada da gaiola "downstream". Este valor de torque memorizado é comparado com o torque atual da gaiola "upstream" depois da barra ter passado pela gaiola "downstream". A velocidade da gaiola "upstream" é então ajustada, pelo Fator-R, para manter o valor desejado de torque.

\section{$\checkmark$ Controle de Laço}

A finalidade principal da função de controle automático de laço é controlar e manter a laminação livre de tração, através de um laço de material entre duas gaiolas de laminação.

As informações de altura do laço e a detecção do material são fornecidas pelo sensor de laço. A medição do valor é interpretada pelo sistema de controle, fornecendo uma medição em unidade de engenharia $(\mathrm{mm})$. Este valor é 
compensado por uma posição de entrada do laço (ELP), parâmetro do controle do sistema, para definir a posição zero do material.

\section{$\checkmark$ Controle Manual}

O operador pode ajustar a velocidade de referência e o Fator-R, por meio das chaves de cascata sobre a mesa de operação. Isso irá sobrescrever qualquer controle automático e agir na direção da cascata principal. Esta correção manual pode ser utilizada para ajustar a tração em um determinador trecho onde não haja controle automático, ou para corrigir uma variação muito grande onde o controle automático possa falhar.

\section{$\checkmark$ Rastreamento do Material}

O sistema de rastreamento acompanha a barra ao longo de sua passagem pelo laminador. O rastreamento é responsável pela ativação correta dos controles automáticos de tração e laço.

O controle de tração usa o sistema de rastreamento para coletar o ponto exato de medição do torque e habilitar o controle de tração. Já o controle de laço usa o rastreamento da cabeça e da cauda para subir e abaixar o formador de laço e iniciar o controle integral. Outras funções também usam o rastreamento para determinar o sequenciamento correto, tais como liberação do fator de compensação de impacto. A função de detecção automática de sucata também utiliza o sistema de rastreamento para indicar uma possível situação de sucata.

O sistema de rastreamento utiliza sensores de detecção de material e/ou indicação de carga no motor para acompanhar a barra no laminador. O tempo que a barra deve levar para percorrer uma determinada distância é calculado através da velocidade do material e das distâncias entre gaiolas e sensores de detecção de metal quente. A indicação de carga no motor ou o sensor de detecção são usados para verificação e aferição dos tempos calculados.

\section{$\checkmark$ Detecção Automática de Sucata}

Utilizando a posição exata da cabeça a todo momento, o sistema detecta possíveis sucatas durante a laminação automaticamente, e em função desta informação toma decisões importantes para evitar dados ao laminador ou mesmo provocar grandes paradas ou mesmo perdas de material. As decisões podem ser como, por exemplo, picotamento da barra laminada, fechamento do forno, fechamento das snap shears do blocos, etc..

\section{$\checkmark$ Compensação de Impacto}

A compensação de impacto consiste em aumentar a velocidade da gaiola para a entrada da barra, reduzindo assim a caída de velocidade com o impacto da barra na 
gaiola. Após a barra está sendo laminada na gaiola, se corrige a referência de velocidade para aquela determinada pela cascata de velocidades.

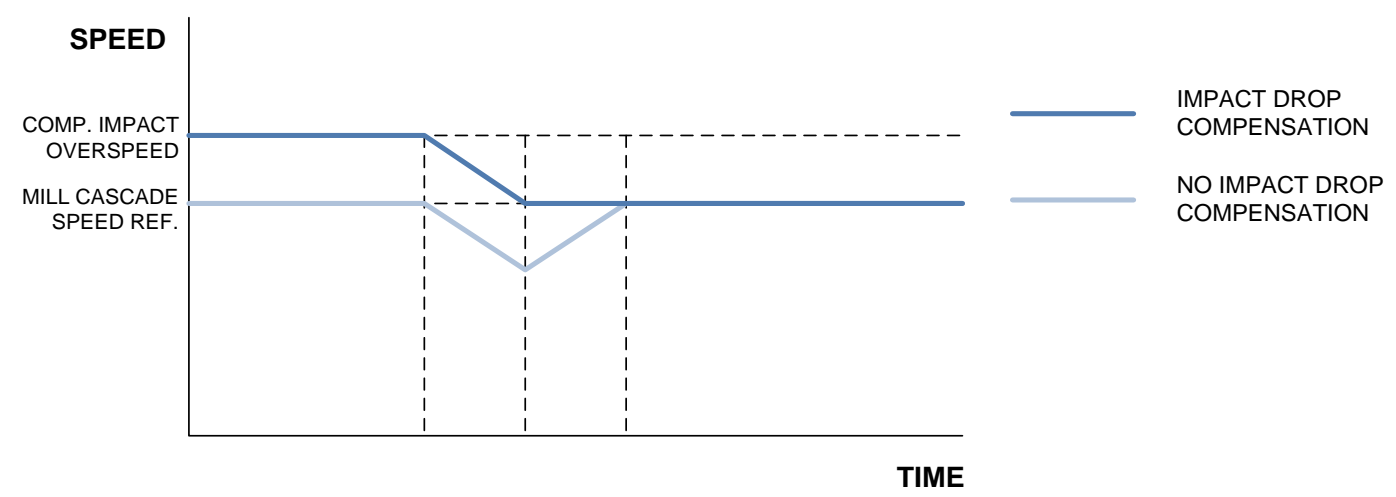

Figura 5. Compensação de Impacto.

\section{$\checkmark$ Tesouras de Desponte}

A função da tesoura de desponte é cortar um pedaço da cabeça ou da cauda, que normalmente apresentam irregularidades, em tamanhos definidos pelo operador.

O controle do disparo utiliza uma HMD (Sensor de detecção de material - hot metal detector) localizada antes da tesoura. Quando a cabeça ou a cauda da barra passa pelo HMD, um bloco integrador começa a calcular a distância percorrida com a velocidade do material, quando este valor atinge o tamanho calculado, o ciclo de corte é acionado (Figura 8).

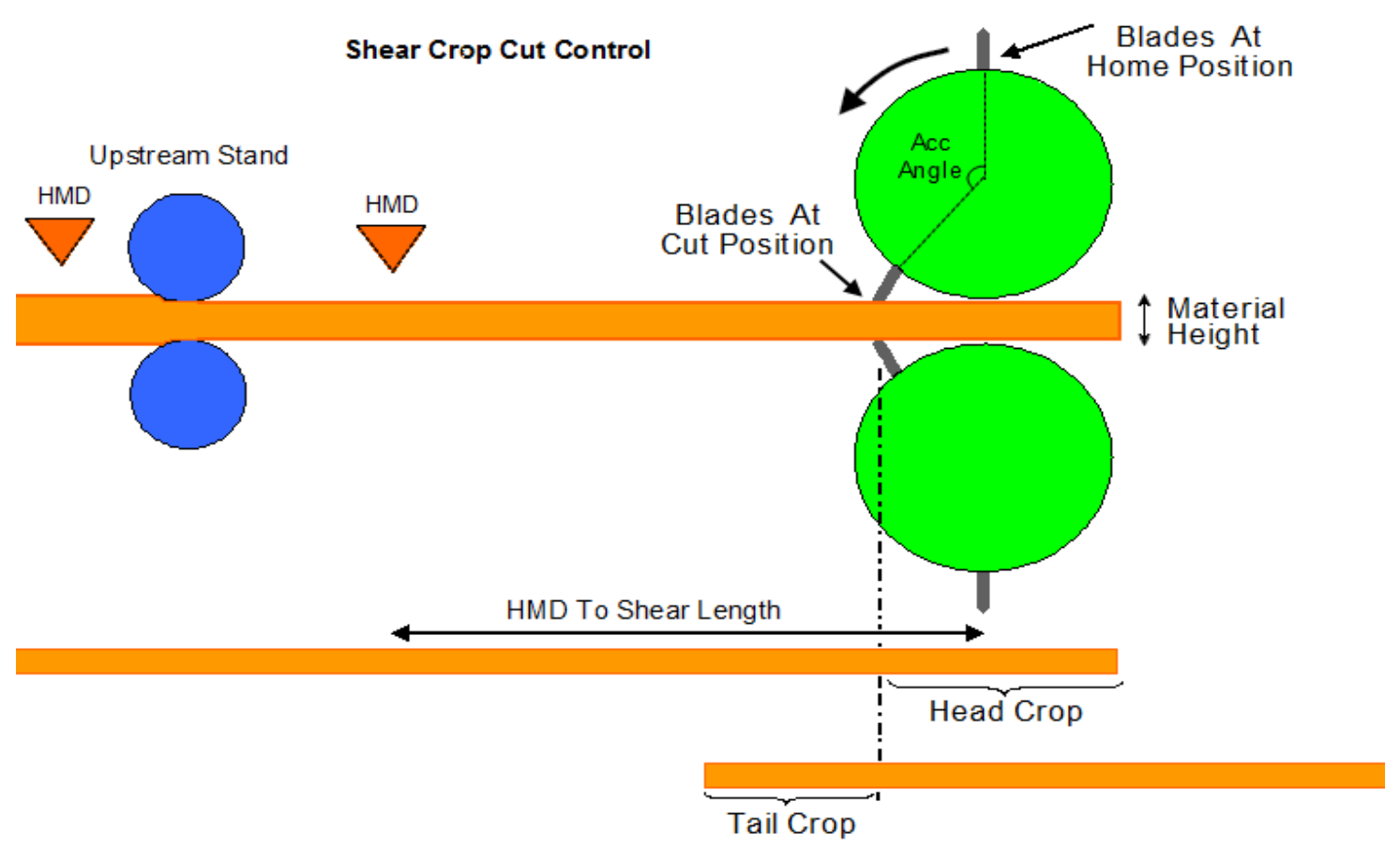

Figura 6. Despontes de Cabeça e Cauda.

$\mathrm{Na}$ IHM dispomos das seguintes opções:

1. Seleção de desponte de cabeça e/ou cauda; e

2. Comprimento do desponte de cabeça e/ou cauda. 


\section{$\checkmark$ Barra Fantasma}

A barra fantasma consiste em uma ferramenta muito importante para o operador do laminador. Esta ferramenta simula efetivamente uma barra no laminador, movimentando tesouras, abrindo água, formando laços, posicionando sistemas. Com isto, o operador pode, antes de iniciar uma corrida após uma parada, certificarse que não há nenhum sistema desligado ou em mal funcionamento, evitando sucatas.

\subsection{Sistema IHM}

O software utilizado para desenvolvimento de toda interface homem máquina (IHM) foi o TIA PORTAL / WinnCC, contendo dois servidores "hot stand-by". Para o sistema de receitas foi utilizado o software para banco de dados SQL. Também houve a inserção de outras ferramentas poderosas, como a supervisão geral do laminador, telas detalhadas de todas as partes do trem, migração de diversos botões físicos para as telas do IHM (reduzindo espaço e poluição visual do púlpito), adição de botões novos e a introdução de uma tela sensível ao toque, com alguns comandos que também podiam ser acessados pelo IHM convencional, caso necessário.
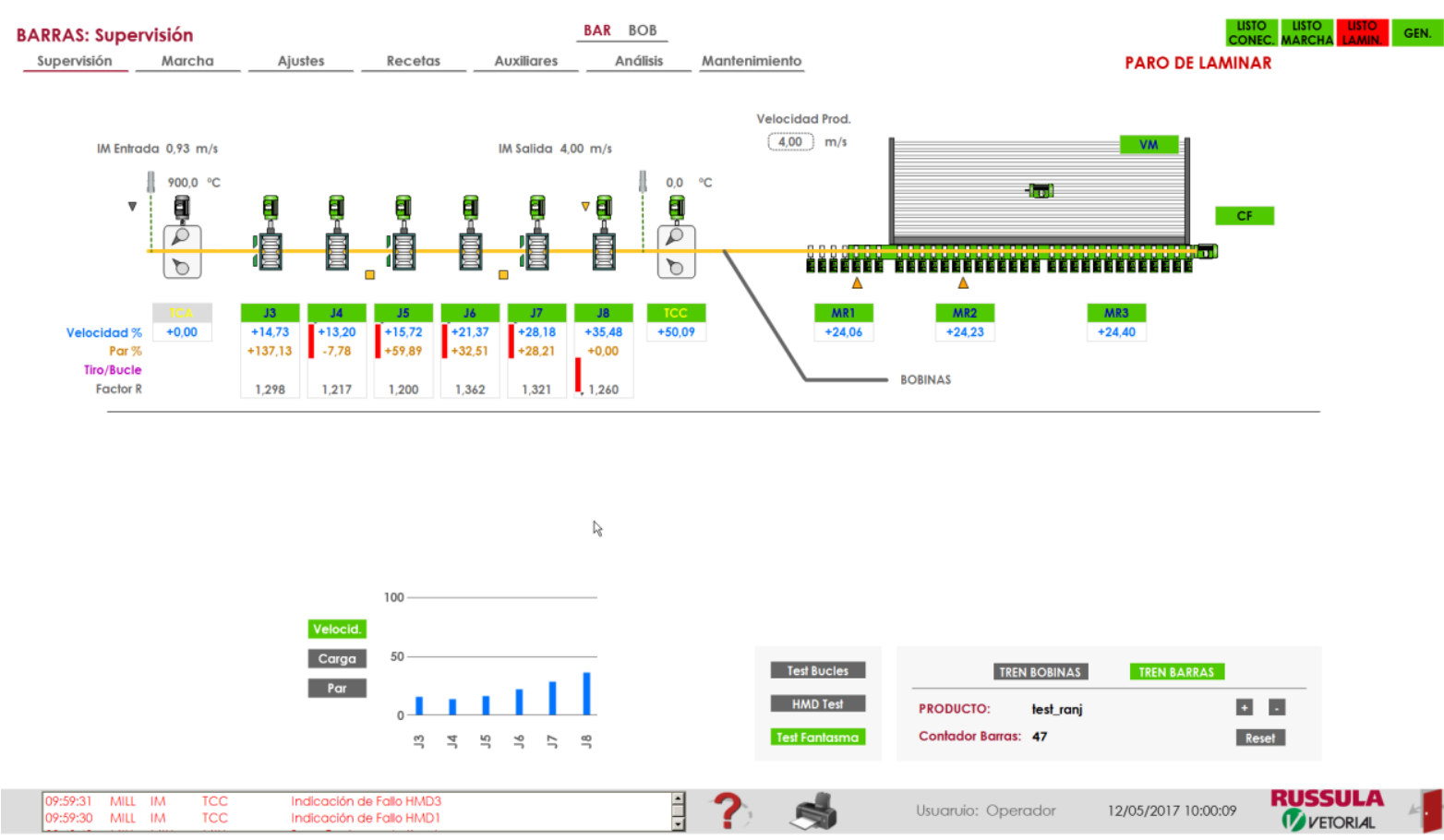

Figura 7. Tela de Supervisão do Laminador de Barras. 


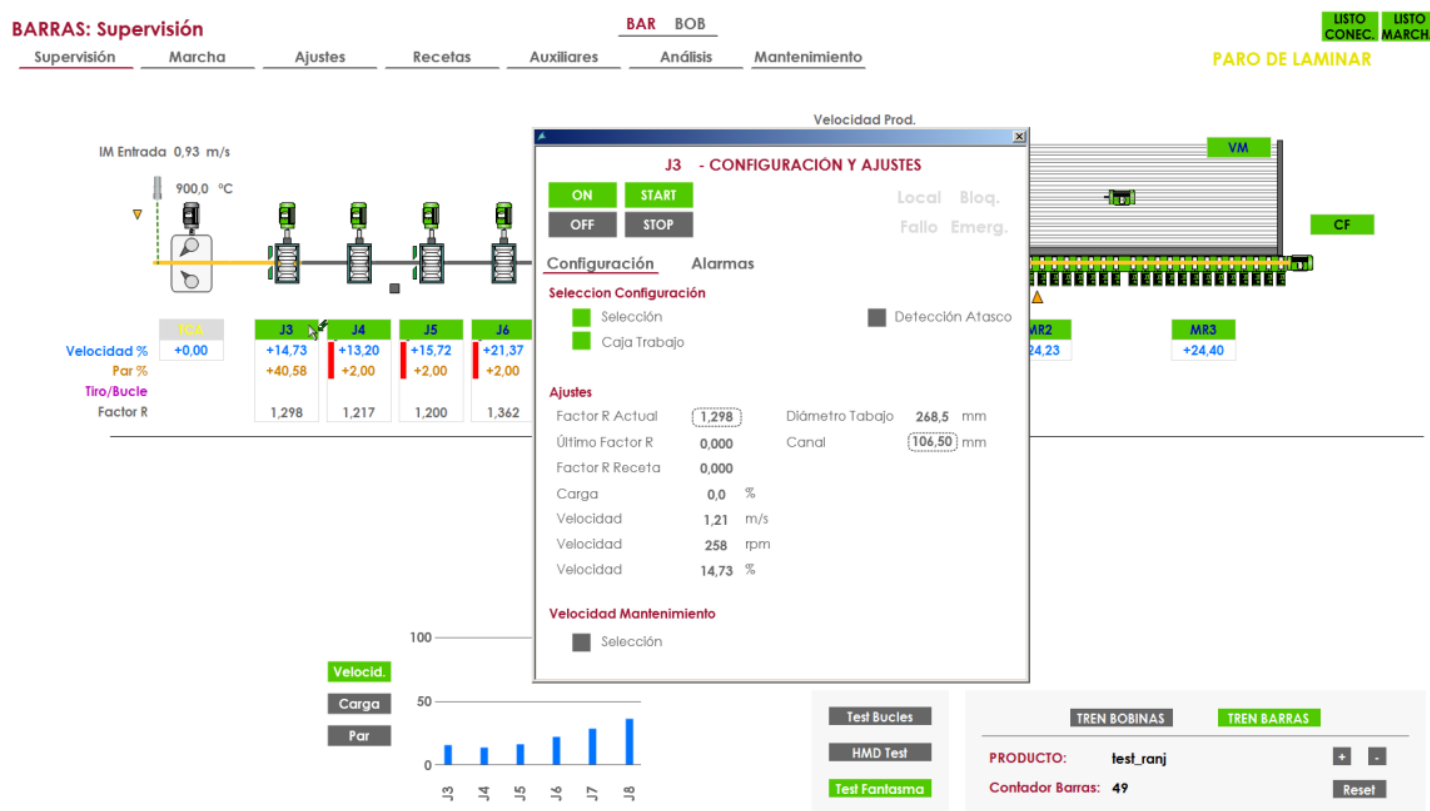

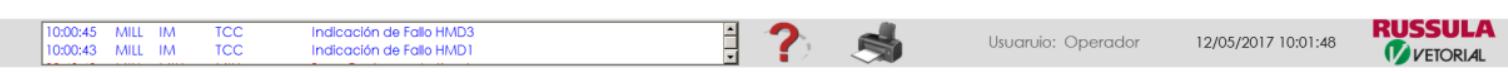

Figura 8. Tela de Supervisão do Lam de Barras com gerenciamento de intertravamentos Gaiola 3.

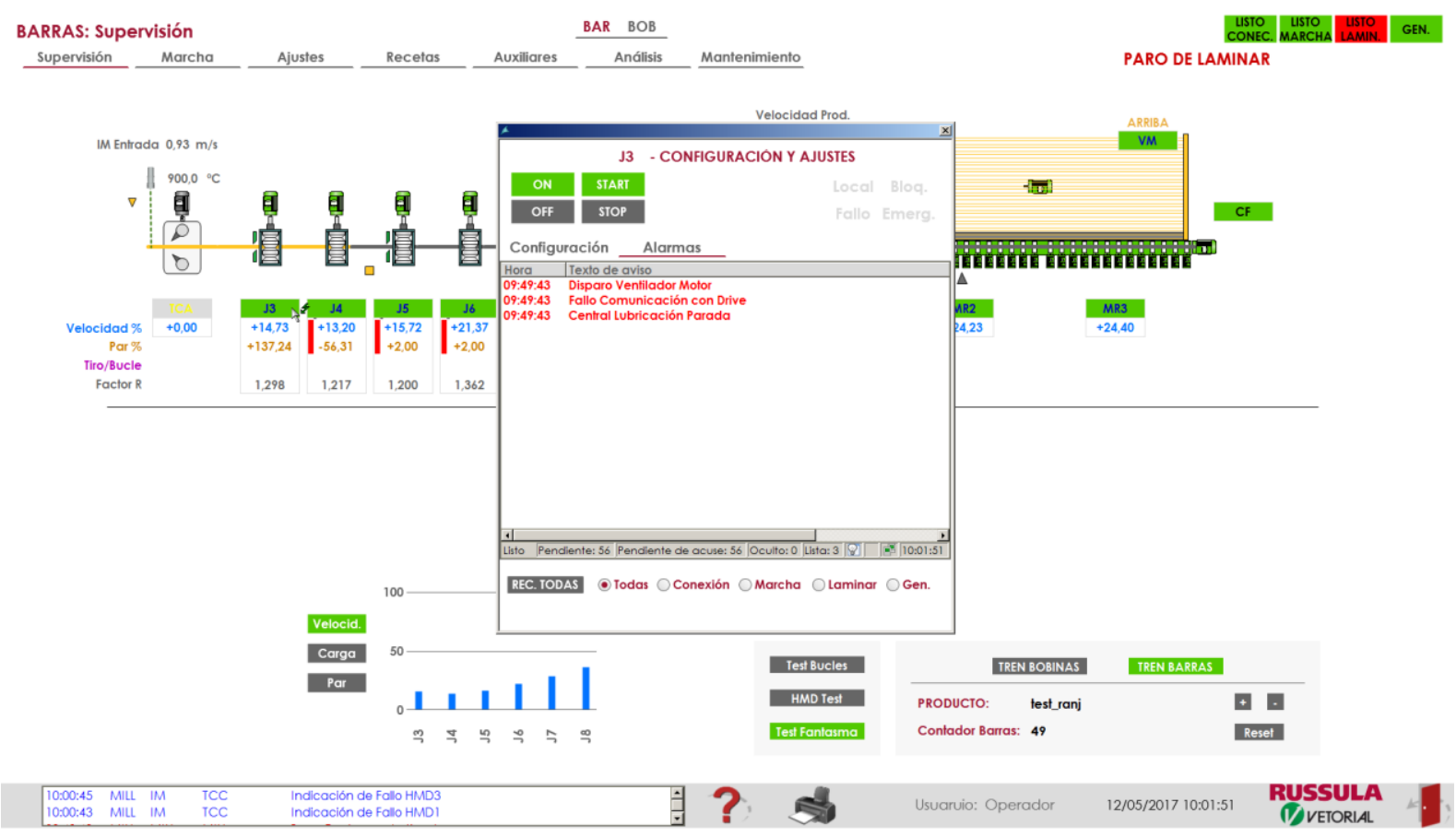

Figura 9. Tela de Supervisão do Lam de Barras com gerenciamento de intertravamentos Gaiola 3. 


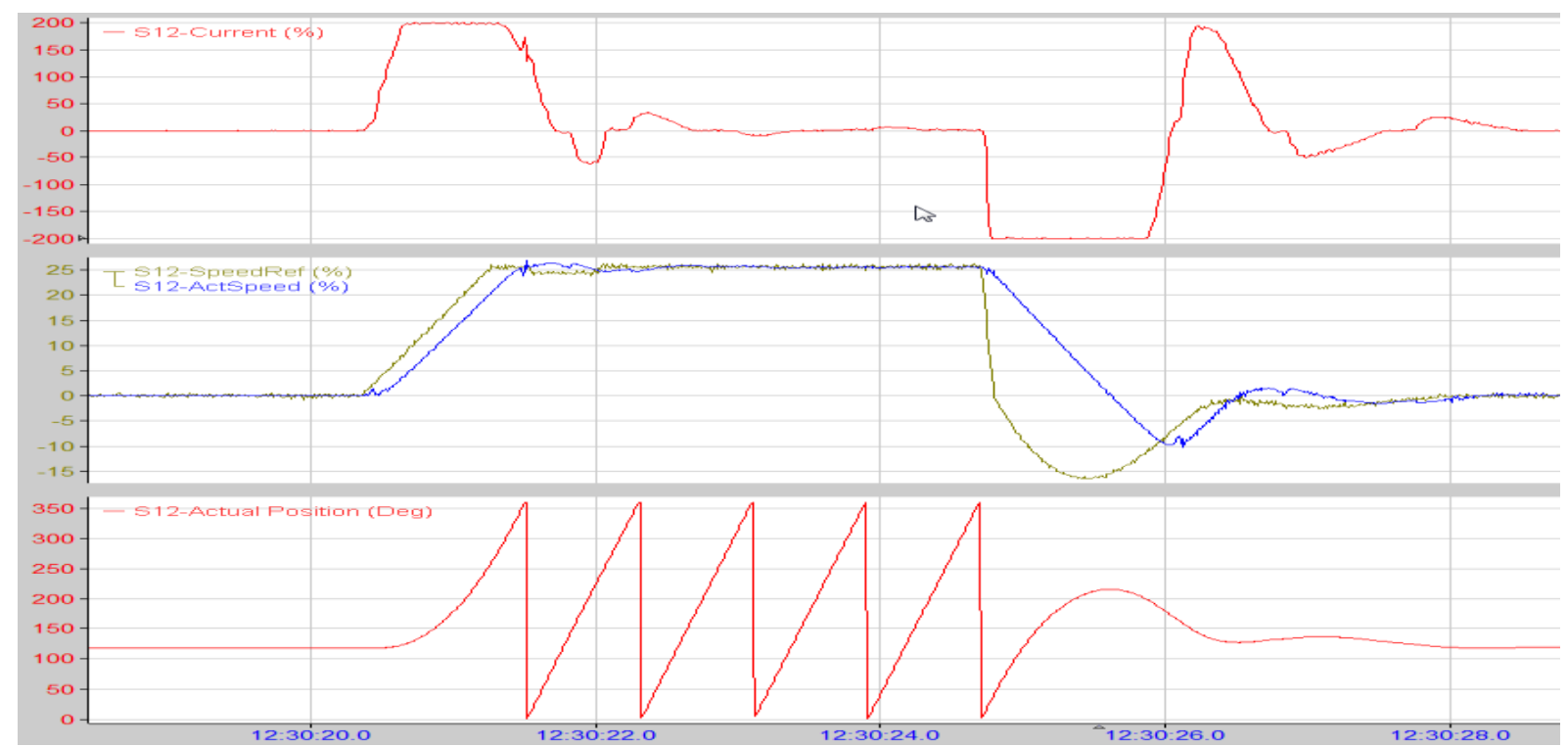

Figura 12. Utilização do Iba para validação de acionamentos.

\subsection{Atualizações dos Equipamentos}

Grande parte dos equipamentos elétricos eletrônicos necessitava ser substituído. Pelo lado dos equipamentos de controle, os PLC's existentes eram da família BBC Procontic. Estes PLC's já estão descontinuados a muitos anos e o fabricante já não existe, assim sendo não há possiblidade de se adquirir sobressalente ou assistência técnica em HW e/ou SW. Assim sendo a troca dos PLC's foi colocada como obrigatória.
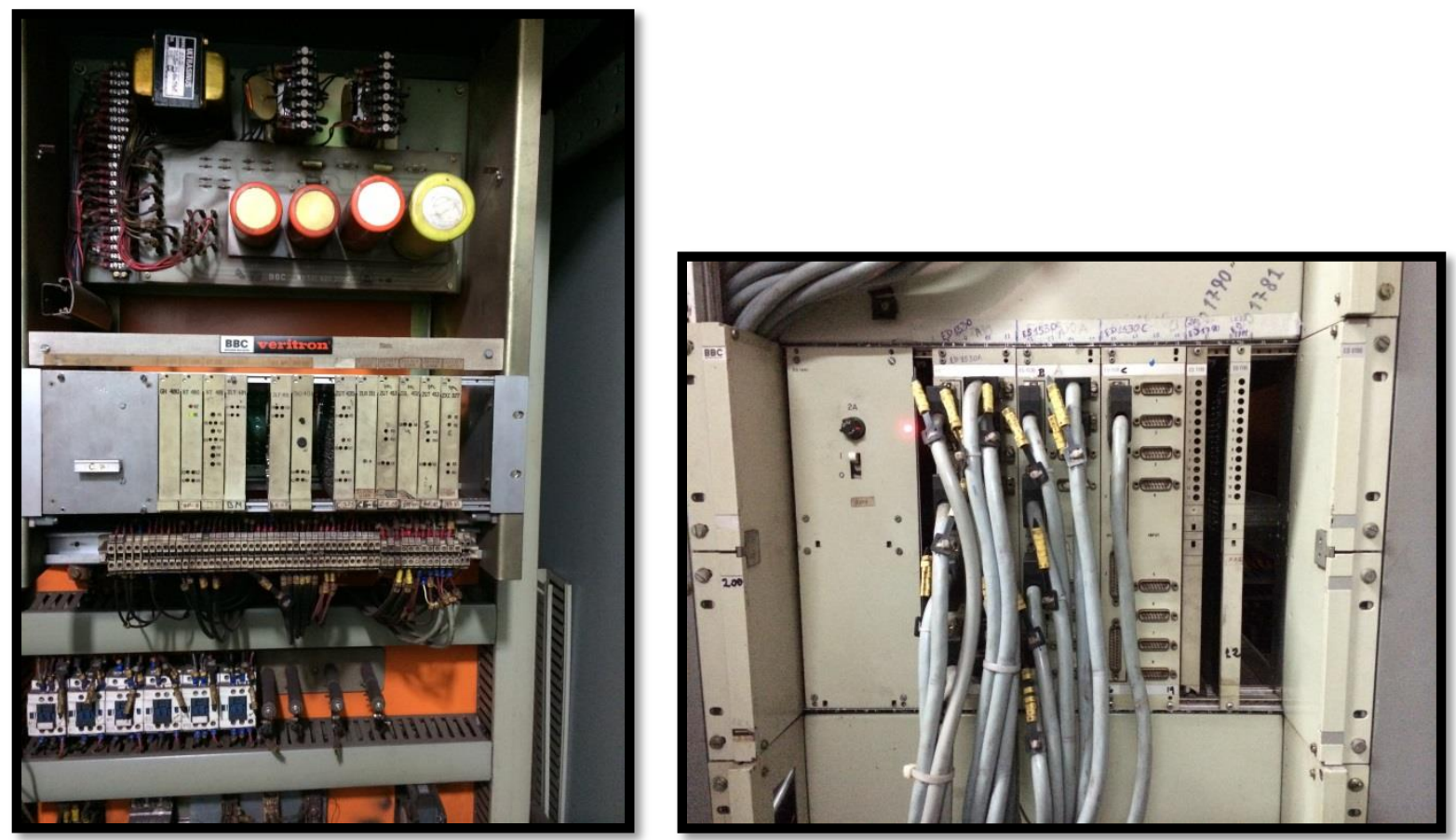

Figura 13. Acionamento BBC VERITRON e PLC PROCONTIC

A nova plataforma de PLC's escolhida para substituir os BBC Procontic, foi a nova linha da Siemens S7-500, que conta com mais capacidade de processamento e 
mais memoria que a antiga $57-400$. A comunicação com as remotas foi definida como Profinet.

Do lado dos conversores de corrente continua existentes, foi feito um levantamento detalhado dos BBC VETRITRON, e por uma questão de ajustes econômicos e estudos de PAY-BACK para o projeto, foi decidido uma solução hibrida amplamente aplicada pela RUSSULA em projetos similares, que é a manutenção da ponte de tiristores antigas (quando estão em bom estado) e somente a troca da parte eletrônica do conversor antigo. Esta solução técnica garante uma redução de custos significativa neste item. Desta maneira os conversores do laminador intermediários serão "digitalizados" com o produto ABB DCR Kit e os demais acionamentos se manterão como VERITRON e a comunicação com o sistema de controle será ainda por I/O's.

\subsection{Organograma}

Durante a parada, a equipe RUSSULA será composta por um total de 07 engenheiros, esses divididos em setores pela planta, afim de otimizar recursos e diminuir o tempo de parada. Foi elaborado um planejamento em conjunto com a VETORIAL para atender todas as metas estabelecidas, atendendo tanto solicitações comerciais quanto operacionais.

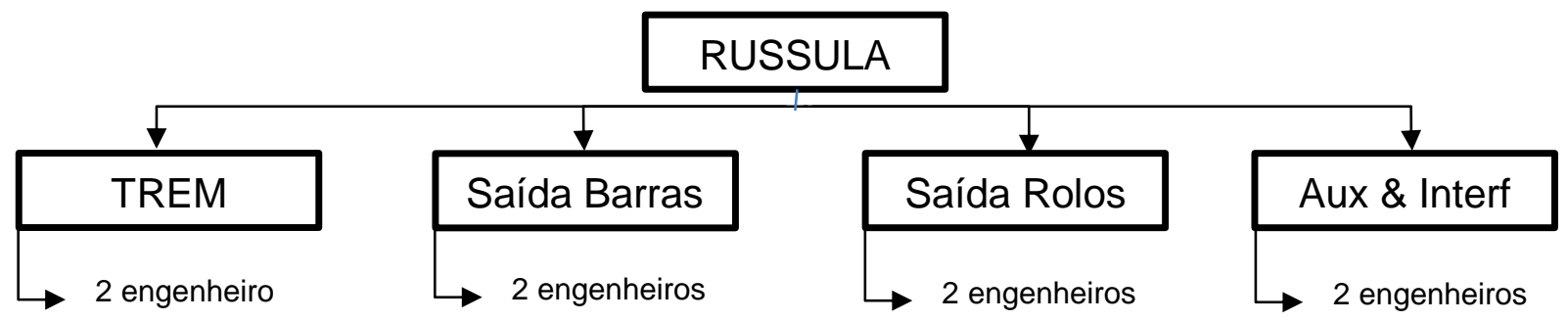

\section{RESULTADOS E DISCUSSÃO}

O Comissionamento esta programado para ocorrer em 10 dias de parada, incluindo os serviços de instalação e montagem elétrica. Estimamos uma curva de aprendizado de 10 dias, ou seja, em 10 dias o laminador deverá atingir a produção nominal anterior a parada.

Como um dos objetivos do projeto é aumentar o nível de utilização do laminador, estima-se que nos meses seguintes ao comissionamento, o produção deve ter um aumento de cerca de até $30 \%$, em razão de melhores rendimentos metálicos, índices de paradas elétricas menores e melhorias operacionais.

Segundo informações da Vetorial Paraguay, hoje a produção mensal é de 6.000 ton/mês. Estimamos que com este projeto possa ser de até 7.800 ton/mês. 


\section{CONCLUSÃO}

Podemos que o projeto é vital para a manutenção operacional do laminador da Vetorial Paraguay, com objetivo de manter a entrega aos clientes.

Ao final do projeto o aumento da produção poderá rapidamente pagar o valor investido no projeto. 